\title{
Thermal conductivity of the gadolinium calcium silicate apatites: Effect of different point defect types
}

\section{Citation}

Qu, Zhixue, Taylor D. Sparks, Wei Pan, and David R. Clarke. 2011. "Thermal Conductivity of the Gadolinium Calcium Silicate Apatites: Effect of Different Point Defect Types." Acta Materialia 59 (10) (June): 3841-3850. doi:10.1016/j.actamat.2011.03.008.

\section{Published Version}

doi:10.1016/j.actamat.2011.03.008

\section{Permanent link}

http://nrs.harvard.edu/urn-3:HUL.InstRepos:34881480

\section{Terms of Use}

This article was downloaded from Harvard University's DASH repository, and is made available under the terms and conditions applicable to Open Access Policy Articles, as set forth at http:// nrs.harvard.edu/urn-3:HUL.InstRepos:dash.current.terms-of-use\#OAP

\section{Share Your Story}

The Harvard community has made this article openly available.

Please share how this access benefits you. Submit a story.

\section{Accessibility}




\title{
Thermal Conductivity of the Gadolinium Calcium Silicate Apatites: Effect of Different Point Defect Types
}

\author{
Zhixue $Q u^{1,}{ }^{*}$, Taylor Sparks ${ }^{2}$, Wei Pan ${ }^{1,}$ and David R. Clarke ${ }^{2}$ \\ ${ }^{1}$ State Key Laboratory of New Ceramics and Fine Progressing, Department of Materials Science \\ and Engineering, Tsinghua University, Beijing 100084, China \\ ${ }^{2}$ School of Engineering and Applied Sciences, Harvard University, Cambridge, MA 02138
}

\begin{abstract}
The gadolinium calcium silicates having the apatite crystal structure can accommodate a wide range of point defects, including oxygen and cation vacancies, as well as anti-site defects, depending on the $\mathrm{Gd} / \mathrm{Ca}$ ratio. Compositions having only cation or oxygen vacancies were identified and the thermal diffusivity and conductivity were measured up to $1000^{\circ} \mathrm{C}$. All the compositions, including the stoichiometric composition, exhibit low thermal conductivities from room temperature to high temperature with the defect-containing compositions having even lower thermal conductivities. The high temperature thermal conductivity, at temperatures below the onset of significant radiative heat transport, decreases with the inverse square root of the cation and anion vacancy concentration, consistent with simple defect scattering models. Based on the data, it is concluded that the oxygen vacancies are slightly more effective in reducing thermal conductivity.
\end{abstract}

* Now at School of Materials Science and Engineering, Beijing University of Technology, Beijing 100124. 


\section{INTRODUCTION}

One of the conventional methods of reducing thermal conductivity of materials is to introduce point defects. Defects act as phonon scattering centers reducing the phonon mean free path and conductivity below that of the perfect crystal. Amongst the classic examples of the effect of site disorder defects on thermal conductivity are substitutional oxygen ions on the nitrogen lattice in AIN [1], isotopic variations in diamond [2, 3], alloying of silicon with germanium $[4,5]$. In the oxides, the most notable example is the effect of yttria-substitution in zirconia, $\mathrm{ZrO}_{2}$, that introduces both site disorder of $\mathrm{Y}^{3+}$ on the $\mathrm{Zr}^{4+}$ site and oxygen vacancies required to charge balance the yttria additions. This is a particularly interesting example since the $\mathrm{Y}^{3+}$ is almost the same mass and size as the $\mathrm{Zr}^{4+}$ and it has been concluded that the reduction in thermal conductivity from that of pure zirconia is almost entirely due to the concentration of oxygen vacancies [6]. When $\mathrm{Hf}^{4+}$ ions, which have almost twice the atomic mass of $\mathrm{Zr}^{4+}$, are substituted into the structure, the thermal conductivity is then reduced [7]. While the introduction of point defects has proven to be a successful strategy for reducing the conductivity of both high conductivity and intermediate conductivity materials at room temperature it remains to be demonstrated that it can also be a useful approach in reducing the conductivity of materials that already have exceptional low conductivity.

The majority of oxides exhibit a temperature dependent, approximately $1 / T$, thermal conductivity [8]. In contrast to this majority, a number of crystalline oxides without vacancies exhibit both a low and a temperature independent thermal conductivity up to $1000^{\circ} \mathrm{C}$. These include $\mathrm{Bi}_{4} \mathrm{Ti}_{3} \mathrm{O}_{12}$ [9], $\mathrm{Sr}_{2} \mathrm{Nb}_{2} \mathrm{O}_{7}$ [10], the Rare-Earth Strontium Aluminates [11] and $\mathrm{Gd}_{8} \mathrm{Ca}_{2}\left(\mathrm{SiO}_{4}\right)_{6} \mathrm{O}_{2}$ [12]. The last, a rare-earth silicate with the apatite structure, is of particular interest since it is capable of forming a variety of different point defects depending on the ratio of the cations on the different crystallographic sites. Specifically, oxygen vacancies, cation 
vacancies and possibly oxygen interstitials can all be formed by appropriate choice of composition as will be described in the following section. This material therefore provides an opportunity to test whether point defects can reduce the already low thermal conductivity further as well as ascertaining the relative effectiveness of different point defects on thermal conductivity.

\section{COMPOSITIONAL DESIGN FOR DIFFERENT POINT DEFECTS}

Rare-earth silicates with the apatite structure have been widely investigated in the last ten years because of interest in using them as solid oxide fuel cell electrolytes on account of their high ionic conductivity [13-21]. The apatite structured rare-earth silicates, which usually crystallize in the hexagonal system with the space group of $\mathrm{P} 6_{3} / \mathrm{m}$, can be represented with a general formula of $\mathrm{A}_{6}{ }_{6} 2_{4}\left(\mathrm{SiO}_{4}\right)_{6} \mathrm{O}_{2+\delta}$ where the two different " $\mathrm{A}$ " sites (see $\mathrm{A} 1$ and $\mathrm{A} 2$ in Figure 1) can be occupied by rare-earth ions, alkali metal ions, alkaline earth ions or cation vacancies. The oxygen stoichiometry parameter $\delta$ varies, depending on the net valence of the " $A$ " sites, over the range of -2 to 1 . One of the interesting features of this class of compound is that the composition can be systematically altered by adjusting the relative proportions of alkaline earth cations and rare-earth ions on the "A1" sites to create different populations of oxygen vacancies, cation vacancies and oxygen interstitials.

Of the many rare-earth silicates that exist, we chose $\mathrm{Gd}_{8} \mathrm{Ca}_{2}\left(\mathrm{SiO}_{4}\right)_{6} \mathrm{O}_{2}$ as the stoichiometric compound. It has already been identified as a candidate low conductivity material on account of its large mean atomic weight and flexible network structure. In addition, measurements at UCSB have demonstrated that it has unusually low and temperature independent thermal conductivity $(\sim 1.3 \mathrm{~W} / \mathrm{mK})$ [12]. In the following paragraphs we describe 
the rationale for the selection of the particular compositions we measured and report in this work.

To describe the relationship between composition and point defects, the general formula for the apatite can be rewritten as $\mathrm{Gd}_{8+x} \mathrm{Ca}_{2+y}\left(\mathrm{SiO}_{4}\right)_{6} \mathrm{O}_{2+3 x / 2+y}$. In this representation, the stoichiometric compound $\mathrm{Gd}_{8} \mathrm{Ca}_{2}\left(\mathrm{SiO}_{4}\right)_{6} \mathrm{O}_{2}$, for which $x=0$ and $y=0$, all the crystallographically allowed sites are occupied. This stoichiometric composition can also be considered the origin of a compositional and defect space diagram shown in figure 2. From the origin of this diagram, three different types of point defects can be expected to form by adjusting the values of $x$ and $y$. In the left quadrants of the diagram, $x<0$, oxygen vacancies or/and cation vacancies are expected with decreasing number of $\mathrm{Gd}^{3+}$ ions. For the relation, $y=-x$, all the " $A$ " cation sites are occupied by either $\mathrm{Gd}^{3+}$ or $\mathrm{Ca}^{2+}$ ions and oxygen vacancies form on the $\mathrm{O} 4$ sites to maintain electrical neutrality. There are no cation vacancies but the concentration of oxygen vacancies increases linearly with decreasing number of $\mathrm{Gd}^{3+}$ ions as indicated by the negative slope of the line. Moreover, in the apatite structure, although the A2 site is in the larger channel, the volume of that site is smaller than that of the A1 site because of the existence of $\mathrm{O} 4$ ions in the center. On the other hand, the $\mathrm{O} 4$ oxygen ions coordinated to $\mathrm{A} 2$ site do not belong to any $\left[\mathrm{SiO}_{4}\right]^{4-}$ tetrahedral unit and are the so-called "free oxygen ions" [22], while all of the oxygen ions coordinated to $\mathrm{A} 1$ site belong to the $\left[\mathrm{SiO}_{4}\right]^{4-}$ tetrahedra. This difference results in the average covalence of the $A 2$ site being higher than that of the $A 1$ site. Therefore, in the $\mathrm{Gd}_{8+\mathrm{x}} \mathrm{Ca}_{2+y}\left(\mathrm{SiO}_{4}\right)_{6} \mathrm{O}_{2+3 \mathrm{x} / 2+\mathrm{y}}$ system, the $\mathrm{Gd}^{3+}$ ions with smaller ionic radius and higher valence usually occupy the $\mathrm{A} 2$ sites while the $\mathrm{Ca}^{2+}$ ions with larger ionic radius and lower valence as well as the cation vacancies probably form on the A1 sites [23]. On the basis of this argument, all of the $\mathrm{A} 1$ sites are occupied by $\mathrm{Ca}^{2+}$ ions in $\mathrm{Gd}_{6} \mathrm{Ca}_{4}\left(\mathrm{SiO}_{4}\right)_{6} \mathrm{O}$ when $x=-2, y=$ 
2. This sets the compositional boundary on the left side of the quadrant in figure 2.

In the right hand quadrants, where $x>0$, a combination of oxygen vacancies, cation vacancies or/and oxygen interstitial ions can be expected to form depending on the proportion of $\mathrm{Gd}^{3+}$ and $\mathrm{Ca}^{2+}$ ions. However, there are two series of compositions of particular interest, corresponding to the formation of a single type of point defect. For compositions along the line $y=-3 x / 2$, only cation vacancies form with all the 04 oxygen sites being occupied. This line terminates at $x=4 / 3$ and $y=-2$, at the composition $\mathrm{Gd}_{9.333}\left(\mathrm{SiO}_{4}\right)_{6} \mathrm{O}_{2}$. The other line of compositions of special note is represented by the dashed line from the stoichiometric composition to the compound $\mathrm{Gd}_{10-z} \mathrm{Ca}_{z}\left(\mathrm{SiO}_{4}\right)_{6} \mathrm{O}_{3-\mathrm{z} / 2}(0 \leq \mathrm{z}<2)$. Along this line all the cation sites are occupied and excess oxygen ions are speculated to appear near $\mathrm{O} 4$ site as the interstitial ion 05 because of the excess positive valence. Of this series, only the end composition $\mathrm{Gd}_{10}\left(\mathrm{SiO}_{4}\right)_{6} \mathrm{O}_{3}$ was investigated in the present work.

To investigate the effect of the three possible point defects independently, seven different compositions were evaluated, labeled 1 to 7 in Table I, corresponding to different values of $x$ and $y$ of the formula unit.

\section{EXPERIMENTAL DETAILS}

\subsection{Materials.}

All the materials were synthesized by co-precipitation. To do this, the sources of Gd and $\mathrm{Ca}$, the rare-earth oxide and calcium carbonate starting powders, respectively, were first treated separately by eliminating surface hydroxide and / or carbonates to assure accurate compositions. The $\mathrm{Gd}_{2} \mathrm{O}_{3}$ (Sigma-Aldrich, purity $\geq 99.9 \%$ ) was calcined at $1000{ }^{\circ} \mathrm{C}$ for $10 \mathrm{~h}$ and 
the $\mathrm{CaCO}_{3}$ (Alfa Aesar, purity $\geq 99.99 \%$ ) was calcined at $250{ }^{\circ} \mathrm{C}$ for $3 \mathrm{~h}$. The freshly heated $\mathrm{Gd}_{2} \mathrm{O}_{3}$ and $\mathrm{CaCO}_{3}$ powders were then weighed in the appropriate stoichiometric ratios and dissolved in nitric acid with continual stirring for $30 \mathrm{~min}$ to form nitrate solutions. The source of silica used was tetraethyl orthosilicate $\left(\mathrm{Si}(\mathrm{OEt})_{4}, \mathrm{TEOS}\right.$, purity $\left.\geq 99.99 \%\right)$. Because of the hydrolysis reaction of TEOS in pure water, the solution was mixed with ethanol at the volume ratio of 1:3 to retard the hydrolysis reaction and TEOS was then slowly added into the fully mixed nitrate solution with vigorous stirring for another $30 \mathrm{~min}$. Excess ammonia water was used as precipitant as well as excess ammonium carbonate for the composition with calcium ions. The solution with TEOS was added drop by drop into an excess solution of ammonia water and/or ammonium carbonate with vigorous stirring to obtain gel-like precipitates.

After co-precipitation, the precipitates were centrifuged and washed twice with deionized water followed by washing in ethanol. The washed precipitates were then dried and calcined at $900{ }^{\circ} \mathrm{C}$ for $5 \mathrm{~h}$. Then, the resulting powders were sieved in 325 mesh, pressed into pellets by uniaxial cold pressing (100 MPa) without any binder and sintered in air at $1600{ }^{\circ} \mathrm{C}$ for $10 \mathrm{~h}$.

\subsection{Characterization.}

X-ray diffraction (XRD) was performed to identify the crystallographic phases using an Xray diffractometer (Rigaku, D/max-RB, Japan) with nickel-filtered $\mathrm{Cu}$ K $\alpha$ radiation. The lattice parameters of some samples are calculated from slow step XRD scan data to estimate the theoretical density.

Thermal diffusivity $(\alpha)$ was measured using an Anter Flashline 3000 thermal flash system (Pittsburgh, PA) with a high-speed xenon lamp. All of the samples for thermal diffusivity measurement were machined to be coplanar with a thickness of approximately $1 \mathrm{~mm}$ and a 
diameter of $8 \mathrm{~mm}$. Prior to the measurements, both sides of each sample were coated with two thin layers of $\mathrm{Ti}$ and $\mathrm{Pt}$ using electron beam physical vapor deposition to minimize radiative heat transport through the translucent samples. The $\mathrm{Ti}$ adhesion layer was approximately 10 $\mathrm{nm}$ thick while the Pt layer was about $750 \mathrm{~nm}$. All of the samples were then spray coated with colloidal graphite on both sides to ensure maximum absorption of the xenon flash and maximum emissivity. The thermal diffusivity was measured in pure Ar atmosphere on heating from 35 to $1000{ }^{\circ} \mathrm{C}$ at intervals of $100{ }^{\circ} \mathrm{C}$. A comparison measurement at $100{ }^{\circ} \mathrm{C}$ on cooling down was also taken to ensure the integrity of the coatings. The thermal diffusivity values were determined using the Clark and Taylor model [24] with a standard variation less than 3\%. Heat capacity $\left(C_{p}\right)$ was measured in $\operatorname{Ar}$ atmosphere from 35 to $1100{ }^{\circ} \mathrm{C}$ using a differential scanning calorimeter (DSC, Netzsch, Pegasus 404C, Germany). The values were determined according to the ASTM standard E1269-95 [25] with a standard variation less than 2\%. Bulk density ( $\rho$ ) was measured using the Archimedes technique with an immersion medium of de-ionized water.

The thermal conductivity $\left(\kappa^{\prime}\right)$ was calculated from the measured diffusivity using the standard relationship:

$$
\kappa^{\prime}=\alpha \cdot C_{p} \cdot \rho
$$

Taking the variations of three variables into consideration, the uncertainty of thermal conductivity is estimated to be $\pm 5 \%$. Moreover, since porosity plays an important role in reducing the thermal conductivity of materials, the thermal conductivity values were further normalized to represent those of fully dense samples $(\kappa)$ using the formula[26]:

$$
\kappa^{\prime} / \kappa=1-\frac{3}{2} \Phi
$$

where $\Phi$ is the measured porosity. 
The longitudinal and transverse acoustic speeds in the samples were calculated by determining the transmission interval between two parallel surfaces of sample using an ultrasonic instrument (ultrasonic pulser/ receiver, Panametrics, 5900PR, US).

\section{RESULTS}

\subsection{Phase Identification.}

X-ray diffraction patterns of the seven compositions are shown in Figure 3. The majority of the lines corresponded to the standard XRD spectrum of the rare-earth silicate apatites (ICDD PDF No. 28-0212) and these are labeled with the crystallographic planes. It can be seen from the figure that the majority of the samples had the single phase apatite structure. Three of the compositions had additional but weak peaks corresponding to a second phase of $\mathrm{Gd}_{2} \mathrm{SiO}_{5}$. Different sintering conditions were investigated to avoid the formation of the $\mathrm{Gd}_{2} \mathrm{SiO}_{5}$ phase but it proved impossible to avoid it. This is similar to reports in the literature indicating that this second phase is observed in the synthesis of other apatite structure compounds [13, $17,18,20,21]$, suggesting that the $\mathrm{Gd}_{2} \mathrm{SiO}_{5}$ phase is very stable. The theoretical densities of the samples were calculated from the XRD lattice parameters data in which the values of standard XRD spectra ICDD PDF No. 28-0212 and No. 38-0283 were adopted for samples 3 and 6, respectively. The relative densities of samples $3 \sim 7$ were all above $98 \%$ while samples 1 and 2 could not be fully densified under the same conditions and had a density of $~ 92 \%$. These results are shown in Table I. No evidence for water incorporation or water adsorption was noted.

Our attempt to synthesize the single phase $\mathrm{Gd}_{10}\left(\mathrm{SiO}_{4}\right)_{6} \mathrm{O}_{3}$ compound containing oxygen interstitial ions was unsuccessful. Other researchers [27] have noted the ability to accommodate oxygen ion interstitials is critically dependent on the size of the rare earth ion 
and decreases as the size of the rare-earth is decreased suggesting that the apatite formed with the Gd may be too small for significant oxygen ion interstitial formation and hence the formation of single phase $\mathrm{Gd}_{10}\left(\mathrm{SiO}_{4}\right)_{6} \mathrm{O}_{3}$. Rather a mixture of the stoichiometric phase and $\mathrm{Gd}_{2} \mathrm{SiO}_{5}$ forms. For this reason the thermal measurements on this composition will be reported but not interpreted in terms of defect scattering models.

\subsection{Heat Capacity.}

Figure 5 shows the temperature dependence of the heat capacity for all of the samples up to about $1100{ }^{\circ} \mathrm{C}$. As can be seen, all of the curves are smooth without any discontinuity, suggesting that there is no phase transformation for all of the samples up to $1100^{\circ} \mathrm{C}$. As expected, the heat capacity decreases with compositions from 1 to 7 , as the concentration of $\mathrm{Gd}^{3+}$ ions increases and the $\mathrm{Ca}^{2+}$ ions simultaneously decreases. To check the accuracy of the experimental data, the heat capacities were calculated according to the Neumann-Kopp rule from the chemical compositions and the literature data $[28,29]$ of its constituent oxides. Because of the polymorphism of $\mathrm{SiO}_{2}$, the data of low cristobalite and high cristobalite were selected to calculate the theoretical heat capacity. The comparison of calculated data with the experimental ones indicates a variation of less than $3 \%$ over the whole temperature range. The measurement uncertainty in the experimental data is approximately the same as the size of the symbols in figure 5 .

\subsection{Thermal Diffusivity.}

The thermal diffusivities of the samples as a function of temperature are shown in figure 6 up to $1000^{\circ} \mathrm{C}$. The thermal diffusivity of all the samples decreases with increasing temperature, reaches a minimum at intermediate temperatures and then increases. The 
increase above the minimum is attributed to the increasing importance of radiative transport through the sample. Another feature of the thermal diffusivities at temperatures below the onset of appreciable radiative transport is that the values are low compared to many other oxides, for instance zirconia [7]. The measurement uncertainty in the experimental data is approximately the same as the size of the symbols in figure 6.

\subsection{Thermal Conductivity.}

The thermal conductivities, calculated from the measured diffusivities using equation 1 and corrected for density variations (equation 2), are shown in figure 7 as a function of temperature up to $600^{\circ} \mathrm{C}$. The measurement uncertainty in the thermal conductivity is about $\pm 0.1 \mathrm{~W} / \mathrm{mK}$ at each of the temperatures. (Above about $700^{\circ} \mathrm{C}$, the significant contribution of radiative transport to the thermal diffusivity renders the calculation of conductivity inappropriate and so the values are not plotted). The most striking features of the data is that thermal conductivities of all the compositions are very low and almost temperature independent. Furthermore, the compositions containing either oxygen vacancies or appreciable cation vacancies have lower thermal conductivities than the stoichiometric or nearstoichiometric compositions. Similarly, the composition containing oxygen interstitial defects has the same conductivity, within experimental uncertainty, as does the stoichiometric composition. These results will be discussed in the following section.

\section{DISCUSSION}

The results presented in the previous section raise three main questions: (i) why the thermal conductivities, even of the stoichiometric composition, are so low, (ii) why the thermal conductivity depends on the composition through the relative proportions of the $\mathrm{Gd}^{3+}$ and $\mathrm{Ca}^{2+}$ ions, and (iii) why the measured conductivities are relatively independent of temperature, 
much less than the $1 / T$ dependence usually cited for insulating materials. Each question is addressed in turn below.

The thermal conductivities of the rare-earth silicate apatite compositions shown in figure 7 are unusually low, even the stoichiometric composition, $\mathrm{Gd}_{8} \mathrm{Ca}_{2}\left(\mathrm{SiO}_{4}\right)_{6} \mathrm{O}_{2}$. For instance, they are all lower than that of either fused silica or yttria-stabilized zirconia. The rareearth apatites match many of the criteria presented in reference [30] for exhibiting low thermal conductivity, for instance, having a large average atomic mass, several sub-lattices on which defects can form and a "flexible" structure. Indeed, these were the reasons these rare-earth silicate apatites were initially identified for this study. On this basis, it is tempting to draw an analog with other silicates, including silica, many of which are known to have low thermal conductivities. However, in contrast to fused silica and quartz [31], the rare-earth silicates are not silica network formers per-se and the silica tetrahedra are connected, instead, through cationic ionic linkages as shown in figure 1 rather than by apex or edge sharing of the tetrahedral in many silicates. Another feature of the apatite structure that suggests some unusual "flexibility" is that it can be described in terms of cation polyhedra forming trigonal prisms along the (001) projection of the 01-A1-O2 that can twist from regular trigonal prisms to distorted metaprisms [32]. This twisted metaprism structure modifies the effective coordination of the cations and the unit cell volume and so one implication of this metaprism structure is that it can be expected to twist and change volume in response to acoustic phonon propagation and thereby decreases thermal conductivity. Detailed high angular resolution, synchrotron-based, X-ray diffraction is necessary to determine the values of the twist angle, $\varphi$, for the compositional series investigated in this work but it is expected that the metaprism twist angle would be the smallest for the stoichiometric compound and increase linearly when 
the structure incorporates cation and oxygen vacancies as a mechanism for reducing unit cell volume.

An estimate of the thermal conductivity of the stoichiometric composition can be made if it is assumed that the phonon mean free path equals the inter-atomic spacing and the conductivity approaches the high-temperature limit. The minimum thermal conductivity can then be approximated [30] by the equation:

$$
\kappa_{\min } \approx 0.87 k_{B} \Omega_{O}^{-2 / 3}\left(\frac{E}{\rho}\right)^{1 / 2}
$$

Here $k_{B}$ is Boltzmann's constant, $\Omega_{O}$ is the average volume per atom, $E$ is the elastic modulus and $\rho$ is the mass density. The unit cell contains 42 atoms and has a volume of $0.530 \mathrm{~nm}^{3}$. The Young's modulus is $160 \mathrm{GPa}$ and the density is $6000 \mathrm{~kg} / \mathrm{m}^{3}$. Substituting into equation 3 , the minimum conductivity is estimated to be $1.14 \mathrm{~W} / \mathrm{mK}$, somewhat lower than the experimental value of $1.45 \mathrm{~W} / \mathrm{mK}$ but nevertheless consistent with the conductivity being limited by the phonon mean free path approaching inter-atomic dimensions. Furthermore, the large number of atoms in the unit cell implies that a substantial proportion of the specific heat is associated with optical modes and the contribution to the thermal conductivity is less than would be calculated assuming that all the heat is propagated by the acoustic modes as is assumed in the models for lattice thermal conductivity of simple structures. From these arguments, it can be seen that the low thermal conductivity is a consequence of the apatite structure having a combination of high mean atomic mass, large mean atomic volume, a large number of atoms per unit cell as well as a low specific modulus.

The dependence of the thermal conductivity on composition is illustrated when the data from figure 7 in the range of $400-600^{\circ} \mathrm{C}$ is plotted in figure 8 in terms of the notional 
concentration of point defects and the type of point defects. If the average atomic mass, $\bar{M}$, alone determined conductivity, as it does for defect-free materials, the thermal conductivity would be expected to vary as $\kappa \propto \overline{\mathrm{M}}^{-1 / 2}$ [33]. The thermal conductivity would then be the highest for the $\mathrm{Gd}_{6} \mathrm{Ca}_{4}\left(\mathrm{SiO}_{4}\right)_{6} \mathrm{O}$ composition $(x=-2)$ and decrease with increasing values of $x$ to the $\mathrm{Gd}_{10}\left(\mathrm{SiO}_{4}\right)_{6} \mathrm{O}_{3}$ composition. (The average atomic masses are listed in Table I). This is clearly not the case. As can be seen from figure 8, the thermal conductivities decreases with the increasing concentration of either oxygen or cation vacancies away from approximately the stoichiometric composition $\mathrm{Gd}_{8} \mathrm{Ca}_{2}\left(\mathrm{SiO}_{4}\right)_{6} \mathrm{O}_{2}$. (A defect concentration of one per unit cell corresponds to a concentration of $\sim 2.4$ at\% relative to the stoichiometric compound). Although the stoichiometric composition $\mathrm{Gd}_{8} \mathrm{Ca}_{2}\left(\mathrm{SiO}_{4}\right)_{6} \mathrm{O}_{2}$ sample was phase pure by X-ray diffraction, back-scatter electron images reveal the presence of a minor concentration of a second phase, suggesting that the composition was slightly off. This is consistent with the peak in thermal conductivity lying somewhere between the conductivities shown for the compositions of samples \#3 and \#4.

The data in figure 8 provides an opportunity to compare the relative effectiveness of various defects, cation and anion vacancies as well as anti-site defects, on the phonon scattering in the apatite structure using existing models for thermal conductivity. The reduction in thermal conductivity of a perfect, pure solid by introducing defects was first analyzed by Klemens [34] and then later by Callaway and von Baeyer [35] using the formalism introduced by Callaway [36]. The basis of these models being that point defects scatter phonons thereby reducing thermal conductivity. This is in addition to the usual anharmonic scattering amongst phonons and reduces thermal conductivity by reducing the phonon mean free path. In these and other models, based on assuming a Debye phonon spectrum, the thermal conductivity at 
temperatures above the Debye temperature is inversely dependent on the square root of the defect phonon scattering coefficient,

$$
\kappa \propto \Gamma^{-1 / 2}
$$

(There is also a model-dependent temperature dependence, which we will discuss in the third part of the discussion). The scattering coefficient, $\Gamma$, explicitly depends on the concentration of defects, $x_{i}$, the mass of the defect, $M_{i}$, and its atomic size, $\delta_{i}$, as well as the average mass, $\bar{M}$, and the mean atomic size of the atoms in the solid, $\bar{\delta}$ :

$$
\Gamma_{i}=x_{i}\left[\left(\frac{M_{i}-\bar{M}}{\bar{M}}\right)^{2}+\varepsilon\left(\frac{\delta_{i}-\bar{\delta}}{\bar{\delta}}\right)^{2}\right]
$$

$\varepsilon$ is a parameter that describes the size misfit. (In his original work, Klemens did not introduce the average mass as he was concerned with small defect concentrations but it was introduced later in considering a defect in a material that contained more than one species. This is variously described as an effective medium, composite or virtual crystal approximation to the problem of describing the multi-component material in which the defect is embedded). Thus, the scattering depends on the concentration of the defects and their "mass contrast", $\Delta M^{2}=\left(M_{i}-\bar{M}\right)^{2}$ and "size misfit contrast", $\Delta \delta=\left(\delta_{i}-\bar{\delta}\right)^{2}$. In the following, the size misfit is not considered since insufficient information is available for the effective size of the ions and vacancies.

The calculation of the effects of multiple defects and other, more complex compounds consisting of several sub-lattices is slightly more complicated than equation 5 since the strength of defect scattering on different sub-lattices can be different. Furthermore, the defect 
concentration and mean atomic mass are coupled. This is the case for the apatites studied in this work. To proceed, we express the apatite composition in its most general form,

$$
A_{u} B_{v} C_{w} D_{z}
$$

Here the capital letters refer to the atoms on the different sub-lattices and the subscripts refer to the number of atoms on these sites. $A$ and $B$ here refer to the cations and vacancies on the crystallographic $\mathrm{A} 2$ and $\mathrm{A} 1$ lattice sites of the apatite, respectively, $\mathrm{C}$ refers to the $\left(\mathrm{SiO}_{4}\right)_{6}$ tetrahedra and $\mathrm{D}$ refers to the anions and vacancies on the $\mathrm{O}$ sub-lattice. The overall scattering strength associated with defects on the different sub-lattices can be expressed as the weighted sum of the scattering strengths of defects on each sub-lattice $[5,37]$ :

$$
\begin{gathered}
\Gamma=\frac{u}{(u+v+w+z)}\left(\frac{M_{A}}{\bar{M}}\right)^{2} \Gamma(A)+\frac{v}{(u+v+w+z)}\left(\frac{M_{B}}{\bar{M}}\right)^{2} \Gamma(B)+\frac{w}{(u+v+w+z)}\left(\frac{M_{C}}{\bar{M}}\right)^{2} \Gamma(C) \\
+\frac{z}{(u+v+w+z)}\left(\frac{M_{D}}{\bar{M}}\right)^{2} \Gamma(D)
\end{gathered}
$$

The denominator $(u+v+w+z)$ is the total number of atoms in the unit cell (42 for the apatites). The parameter, $M_{A}$, is the average mass of the atoms on the A lattice sites and $\bar{M}$ is the mean mass of the atoms in the unit cell. $\Gamma(A)$ is the scattering strength associated with defects on the A lattice sites, and similarly for the scattering strength associated with the other sites, B, C and D. The scattering for each type of site depends on the presence of defects on that site. If there are no defects, for instance, on the $\mathrm{A} 2$ site and the $\mathrm{SiO}_{4}$ tetrahedra sites in the apatites investigated in this work, then from equation 5 the scattering strength from those sites, $\Gamma(A)$ and $\Gamma(C)$, is zero. So, the overall scattering strength for the apatites investigated in 
this work is reduced to the mass disorder and vacancies on the $A 1$ site and vacancies on the $O$ sites:

$$
\Gamma=\frac{4}{42}\left(\frac{M_{B}}{\bar{M}}\right)^{2} \Gamma(B)+\frac{2}{42}\left(\frac{M_{D}}{\bar{M}}\right)^{2} \Gamma(D)
$$

The possibility of both mass disorder and vacancies on the $\mathrm{A} 1$ site means that the mass contrast for the scattering strength $\Gamma(B)$ must include the contributions from each. Following, Berman et al, [38], who considered the effect on phonon scattering from multiple isotopes on the same lattice, the total effect of several defects is proportional to the variance of the masses on the sub-lattice weighted by their fractional concentrations, $f_{j}$ :

$$
\overline{(\Delta M)^{2}}=\sum_{j} f_{j}\left(M_{j}-\bar{M}\right)^{2}
$$

where $f_{j}$ are the fractional concentration on the sublattice of the defect types $j$, for instance the concentration of vacancies and anti-site defects, such as Gd on a Ca site. Consequently, the scattering strength of a site, B, with different defects can be expressed as:

$$
\Gamma(\mathrm{B})=\frac{\overline{\left(\Delta M_{B}\right)^{2}}}{\left(\bar{M}_{B}\right)^{2}}=\frac{\sum_{j} f_{j}\left(M_{j}-\bar{M}_{B}\right)^{2}}{\left(\bar{M}_{B}\right)^{2}}
$$

and the average mass here refers to the average mass of the atoms on the site, B. A similar equation applies for $\Gamma(D)$.

To apply these equations to the apatites we have investigated, we consider the effect of oxygen vacancies and cation vacancies separately. This simplifies the equations and reflects the fact that concentrations of vacancies on the oxygen and cation sites affect the mean atomic mass of the unit cell differently.

\section{Compositions with oxygen vacancies}


Oxygen vacancies are formed when there is an excess of $\mathrm{Ca}^{2+}$ and the composition can then be expressed, preserving the number of atoms on the different sites, as:

$$
[G d]_{6}\left[G d_{0.5-x / 2} \mathrm{Ca}_{0.5+x / 2}\right]_{4}\left(\mathrm{SiO}_{4}\right)_{6}\left[\mathrm{O}_{1-x / 2} \mathbf{-}_{x / 2}\right]_{2}
$$

Where represents a vacancy and $x$ is the oxygen vacancy concentration per unit cell. The mean atomic mass of the unit cell can be expressed as:

$$
\bar{M}=\frac{1}{42}\left[(8-2 x) M_{G d}+2(1+x) M_{C a}+6 M_{S i O 4}+(2-x) M_{O}\right]
$$

The average mass of the ions on the B sites, $\bar{M}_{B}$, the crystallographic A1 site, is given by:

$$
\bar{M}_{B}=\frac{(1-x)}{2} M_{G d}+\frac{1+x}{2} M_{C a}
$$

and similarly, the average mass on the oxygen sites, $\bar{M}_{D}$, is given by

$$
\bar{M}_{D}=(1-x / 2) M_{O}
$$

The scattering strength resulting from the presence of oxygen vacancies can then be written (equation 9) as:

$$
\Gamma_{O-v a c}=\frac{2}{21}\left(\frac{\bar{M}_{B}}{\bar{M}}\right)^{2}\left[\frac{\overline{\Delta M_{B}^{2}}}{\bar{M}_{B}^{2}}\right]+\frac{1}{21}\left(\frac{\bar{M}_{D}}{\bar{M}}\right)^{2}\left[\frac{\overline{\Delta M_{D}^{2}}}{\bar{M}_{D}^{2}}\right]
$$

where the mass variances on the B-site and D-site depend on oxygen vacancy concentration, $\mathrm{x}$, as:

$$
\begin{aligned}
& \overline{\Delta M_{B}^{2}}=\left(\frac{x}{2}\right)\left(M_{G d}-\bar{M}_{B}\right)^{2}+\left(\frac{x}{2}\right)\left(M_{C a}-\bar{M}_{B}\right)^{2} \\
& \text { and } \overline{\Delta M_{D}^{2}}=\left(\frac{x}{2}\right)\left(M_{O}-\bar{M}_{D}\right)^{2}+\frac{x}{2}\left(M_{v a c}-\bar{M}_{D}\right)^{2}
\end{aligned}
$$


The analytical form for the scattering strength of equation 13 is complicated but to first order is linearly proportional to the oxygen vacancy concentration

$$
\Gamma_{o-v a c} \approx x\left[\frac{\left(M_{G d}-M_{C a}\right)^{2}+4 M_{O}^{2}}{84 \bar{M}^{2}}\right]
$$

and so the thermal conductivity (equation 4) can then be expected to vary with the inverse square root of the oxygen vacancy concentration:

$$
\kappa_{O-v a c} \propto x^{-\frac{1}{2}}\left[\frac{\left(M_{G d}-M_{C a}\right)^{2}+4 M_{O}^{2}}{84 \bar{M}^{2}}\right]^{-\frac{1}{2}}
$$

The full analytical function for the thermal conductivity using equation 13 and the mass variances of equation 14 is shown as the solid line in figure 8 through the data. The R-value for the fit of equation 15 to the data is 0.996 .

\section{Compositions with cation vacancies}

Cation vacancies are formed on the $A 1$ site when there is an excess $\mathrm{Gd}^{3+}$, so there is site disorder associated with both the intermixing of $\mathrm{Gd}^{3+}$ and $\mathrm{Ca}^{2+}$ ions as well as cation vacancies. There are no oxygen vacancies. In this case, the composition can be conveniently expressed as:

$$
[G d]_{6}\left[G d_{0.5+x / 2} \mathrm{Ca}_{0.5-3 x / 4} \mathbf{-}_{x / 4}\right]_{4}\left(\mathrm{SiO}_{4}\right)_{6} \mathrm{O}_{2}
$$

where the cation concentration $\mathrm{x}$ is controlled by the excess $\mathrm{Gd}^{3+}$. For these compositions the mean atomic mass varies with vacancy concentration as:

$$
\bar{M}=\frac{1}{42}\left[(8+2 x) M_{G d}+(2-3 x) M_{C a}+6 M_{S i O 4}+2 M_{O}\right]
$$


Because of the cation vacancies and the variation in $\mathrm{Ca}$ and $\mathrm{Gd}$ concentrations with the concentration of cation vacancies, the average mass of the ions on the $\mathrm{B}$ sites, $\bar{M}_{B}$, is given by:

$$
\bar{M}_{B}=(0.5+x / 2) M_{G d}+(0.5-3 x / 4) M_{C a}
$$

So, the scattering strength resulting from cation vacancies and the associated mass intermixing then becomes

$$
\Gamma_{\text {cation-vac }}=\frac{4}{42}\left(\frac{\bar{M}_{B}}{\bar{M}}\right)^{2}\left[\frac{\overline{\Delta M_{B}^{2}}}{\left(\bar{M}_{B}\right)^{2}}\right]
$$

where the mass variance is

$$
\overline{\Delta M_{B}^{2}}=\left(\frac{x}{2}\right)\left(M_{G d}-\bar{M}_{B}\right)^{2}+\left(\frac{3 x}{4}\right)\left(M_{C a}-\bar{M}_{B}\right)^{2}+\frac{x}{4}\left(M_{v a c}-\bar{M}_{B}\right)^{2}
$$

As with the scattering strength associated with excess of $\mathrm{Ca}^{2+}$ and the compensating anion vacancies, the scattering strength of equation 18 also varies linearly, to first order, with the concentration of cation vacancies. Consequently, the thermal conductivity for compositions with cation vacancies can be expected to vary as:

$$
\kappa_{\text {cation-vac }} \propto x^{-\frac{1}{2}}\left[\frac{5\left(M_{G d}-M_{C a}\right)^{2}+\left(M_{G d}+M_{C a}\right)^{2}}{(\bar{M})^{2}}\right]^{-\frac{1}{2}}
$$

This has a similar functional form as the effect of oxygen vacancies but the magnitude in conductivity reduction is somewhat smaller. The complete function has been fitted by the dashed line to the data in figure 8 . The R-value for the fit to the data is 0.97 .

Finally, we turn now to the temperature dependence of the thermal conductivity. The values shown in figure 7 are intermediate between the classical 1/T dependence of defect-free dielectrics [33] and the temperature-independent conductivity exhibited by highly defective solids, such as yttria-stabilized zirconia $[7,8,26]$, and the temperature-independent 
conductivities of natural superlattice oxides, such as $\mathrm{Bi}_{4} \mathrm{Ti}_{3} \mathrm{O}_{12}$ [9] and $\mathrm{Sr}_{2} \mathrm{Nb}_{2} \mathrm{O}_{7}$ [10]. Indeed, allowing for experimental uncertainties in the measurements of each of the parameters in equation 1, the thermal conductivities can be considered to be almost independent of temperature. The conventional models, again based on a Debye spectrum of phonon energies and Rayleigh phonon scattering by defects, predict that at high temperatures $\left(T>\theta_{D}\right)$, the thermal conductivity can be expressed as:

$$
\kappa=\frac{k_{B} v_{S}^{1 / 2}}{\pi^{3 / 2}} \frac{1}{\sqrt{\Omega_{O} C \Gamma}} \frac{1}{\sqrt{T}} \tan ^{-1}\left[\frac{k_{B} \theta_{D}}{\hbar}\left(\frac{\Omega_{O} \Gamma}{4 \pi v_{S}^{3} C T}\right)^{1 / 2}\right]
$$

where $k_{B}$ is Boltzmann's constant, $\mathrm{C}$ is a temperature-independent parameter that characterizes the anharmonic scattering as a function of phonon frequency, $v_{s}$ is the speed of sound, $T$ is temperature. $\Omega_{\mathrm{o}}$ is the unit cell volume.

Neither this, nor its high temperature limit $\kappa \rightarrow T^{-1 / 2}$, approaches a temperature independent conductivity. However, a refinement of the model that incorporates a cut-off in the phonon frequency corresponding to when the phonon mean free path equals the interatomic spacing predicts that the thermal conductivity transitions at high temperatures to:

$$
\kappa=\frac{2 B \sqrt{T_{0}}}{3} T^{-3 / 2}+\frac{B}{3 T_{0}}
$$

where $B$ is the a function of the physical properties of the material, which for any particular material is a constant and $T_{0}$ is another constant [39]. Since neither of these constants is known a-priori, they have been used as fitting constants [40]. In cases such as our data, the temperature dependence is so weak as to be insufficient to evaluate these two constants independently with any confidence. Under these circumstances it is tempting to conclude that the weak temperature dependence is due to the conductivity being equal to the minimum 
thermal conductivity, sometimes referred to as the glassy-limit [41]. The difficulty in concluding so is that the value of the minimum thermal conductivity should not be affected by the presence of defects and only depend on the average atomic mass as $\bar{M}^{-1 / 2}$. As described earlier the data in figure 8 is not consistent with this expectation. Consequently, it must be concluded at this stage that the standard model for predicting thermal conductivity in these highly defective, but cubic, oxides using a Debye phonon spectrum and assuming Rayleigh phonon defect scattering is inadequate and that the thermal conductivity must either be computed from first principles or the phonon spectrum measured and the conductivity computed from the spectrum. This conclusion is further substantiated by the fact that if the thermal conductivity were controlled by the phonon mean free path being equal to the interatomic distance, then from the Debye equation [33]

$$
\kappa=\frac{1}{3} C_{V} \bar{v} \Lambda
$$

where $\bar{v}$ is the mean phonon velocity, the conductivity would follow the temperature dependence of the specific heat, $C_{V}$, and the conductivity would rise with increasing temperature and above the Debye temperature asymptote to a constant value as the conductivity of fused silica does. Comparison of the temperature dependence of the heat capacity (figure 5) and the thermal conductivity (figure 7) show they do not follow the same temperature dependence as suggested by equation 23 . This strongly suggests that a significant fraction of the high temperature specific heat is associated with optical phonons and hence do not contribute significantly to the thermal conductivity. 


\section{CONCLUSIONS}

A series of rare-earth silicate $\mathrm{Gd}_{8+x} \mathrm{Ca}_{2+y}\left(\mathrm{SiO}_{4}\right)_{6} \mathrm{O}_{2+3 x / 2+y}$ compositions having the apatite crystal structure were synthesized to investigate the effect of different types of point defects on thermal conductivity up to high temperatures. Each composition was selected so that the compound contained just one of three possible types of vacancies or anti-site defects. The results show that the introduction of either oxygen vacancies or cation vacancies into crystal reduces the thermal conductivity, and within the limited number of compounds investigated the values of thermal conductivity decrease as approximately the inverse square root of the concentration of these two point defects.

\section{ACKNOWLEDGEMENT}

This work was supported jointly by the National Natural Science Foundation of China (Grants 50232020 and 50572042) at Tsinghua University and by the Materials World Network of the National Science Foundation through grant DMR-0710523. Some of the experiments were performed at UC Santa Barbara while the first author was there as part of exchange portion of the network program. The authors are indebted to one of the reviewers for pointing out some of the complications associated with the stability of a $\mathrm{Gd}_{10}\left(\mathrm{SiO}_{4}\right)_{6} \mathrm{O}_{3}$ compound containing oxygen interstitials. 


\section{FIGURE CAPTIONS}

1. The crystal structure of the stoichiometric rare-earth apatites $\mathrm{A}_{10}\left(\mathrm{SiO}_{4}\right)_{6} \mathrm{O}_{2+\delta}$. (a) View along the [001] axis and (b) the location of the two types of cation sites, A1 and A2, as well as the oxygen sites, $\mathrm{O} 4$. The blue spheres represent the cations $\mathrm{A}$, such as, rareearth ions, alkaline earth cations or cation vacancies; the red ones, the oxygen anions; and the light-blue tetrahedra represent for the $\left[\mathrm{SiO}_{4}\right]^{4-}$ tetrahedra. No vacancies and oxygen interstitials are shown in the figure.

2. Representational space for displaying the variations in composition away from the stoichiometric composition according to the formula $\mathrm{Gd}_{8+x} \mathrm{Ca}_{2+y}\left(\mathrm{SiO}_{4}\right)_{6} \mathrm{O}_{2+3 \times / 2+y}$.

3. X-ray diffraction patterns of the rare-earth apatites studied. The crystallographic diffraction planes of the apatite phases are labeled. The small peaks labeled with a star are those from a minor volume fraction of $\mathrm{Gd}_{2} \mathrm{SiO}_{5}$.

4. SEM of a polished surface of the stoichiometric composition revealing the presence of a small volume fraction of second phase not detected by X-ray diffraction. Back-scatter electron image.

5. Specific heat as a function of temperature for all the apatite compositions. The measured values are within $\pm 3 \%$ of those calculated using the Neumann-Kopp rule. The measurement uncertainty is smaller than the symbol size.

6. Thermal diffusivity measured by thermal flash up to $1000^{\circ} \mathrm{C}$. The up-turn at temperatures above about $600^{\circ} \mathrm{C}$ is attributed to radiative heat transfer through the thin samples. The lines are guides to the eye.

7. Thermal conductivity derived from the thermal diffusivity as a function of temperature up to $600^{\circ} \mathrm{C}$. The experimental uncertainty in the conductivities is estimated to be 
$\pm 0.1 \mathrm{~W} / \mathrm{mK}$, approximately twice the size of the symbols, and illustrated by the error bars in the lowest curves. The lines through the data are guides to the eye.

8. Thermal conductivity in the range $400-600^{\circ} \mathrm{C}$ as a function of nominal defect concentration per unit cell. One defect per unit cell corresponds to a concentration of $2.4 \mathrm{a} / \mathrm{o}$. The data is compared with the predictions in the text based on oxygen and cation vacancies, equations 15 and 20 in the text, respectively. 


\section{REFERENCES}

[1] Slack GA, Tanzilli RA, Pohl RO, Vandersande JW. The Intrinsic Thermal Conductivity of AIN. Journal of the Physics and Chemistry of Solids 1987;48:641.

[2] Wei L, Kuo PK, Thomas RL, Anthony TR, Banholzer WF. Thermal Conductivity of Isotopically Modified Single Crystal Diamond. Physical Review Letters 1993;70:3764.

[3] Anthony TR, Banholzer WF, Fleischer JF, Wei L, Kuo PK, Thomas RL, Pryor RW. Thermal Diffusivity of Isotopically Enriched ${ }^{12}$ C Diamond. Physical Review B 1990;42:1104.

[4] Abeles B, Beers DS, Cody GD, Dismukes JP. Thermal Conductivity of Ge-Si Alloys at High Temperatures. Physical Review 1962;125:44.

[5] Abeles B. Lattice Thermal Conductivity of Disordered Semiconductor Alloys at High Temperatures. Physical Review 1963;131:1906.

[6] Klemens PG. Phonon Scattering by Oxygen Vacancies in Ceramics. Physica B 1999;263-264:102.

[7] Winter MR, Clarke DR. Thermal conductivity of yttria-stabilized zirconia-hafnia solid solutions. Acta Materialia 2006;54:5051.

[8] Kingery WD. Thermal Conductivity: XII, Temperature Dependence of Conductivity for SinglePhase Ceramics. Journal of the American Ceramic Society 1955;38:251.

[9] Shen Y, Clarke DR, Fuierer PA. Anisotropic Thermal Conductivity of the Aurivillus Phase, Bismuth Titanate $\left(\mathrm{Bi}_{4} \mathrm{Ti}_{3} \mathrm{O}_{12}\right)$ : A Natural Nanostructured Superlattice. Applied Physics Letters 2008;93:102907.

[10] Sparks TD, Fuierer PA, Clarke DR. Anisotropic Thermal Diffusivity and Conductivity in La-Doped Strontium Niobate. Journal of the American Ceramic Society 2010;93:1136.

[11] Wan CL, Sparks TD, Wei P, Clarke DR. Thermal Conductivity of the Rare-Earth Strontium Aluminates. Journal of the American Ceramic Society 2010;93.

[12] Winter MR, Clarke DR. Oxides with Low Thermal Conductivity. Winter Study Group. Santa Barbara, 2007.

[13] Nakayama S, Kageyama T, Aono H, Sadaoka Y. Ionic conductivity of lanthanoid silicates, $\mathrm{Ln}_{10}\left(\mathrm{SiO}_{4}\right)_{6} \mathrm{O}_{3}(\mathrm{Ln}=\mathrm{La}, \mathrm{Nd}, \mathrm{Sm}, \mathrm{Gd}, \mathrm{Dy}, \mathrm{Y}, \mathrm{Ho}, \mathrm{Er}$ and Yb). Journal of Materials Chemistry 1995;5:1801.

[14] Sansom JEH, Richings D, Slater PR. A powder neutron diffraction study of the oxide-ionconducting apatite-type phases, La9.33Si6O26 and La8Sr2Si6O26. Solid State Ionics 2001;139:205.

[15] Higuchi M, Masubuchi Y, Nakayama S, Kikkawa S, Kodaira K. Single crystal growth and oxide ion conductivity of apatite-type rare-earth silicates. Solid State lonics 2004;174:73.

[16] Sansom JEH, Kendrick E, Tolchard JR, Islam MS, Slater PR. A comparison of the effect of rare earth vs Si site doping on the conductivities of apatite-type rare earth silicates. J. Solid State Electrochem. 2006;10:562.

[17] Beaudet-Savignat S, Vincent A, Lambert S, Gervais F. Oxide ion conduction in $\mathrm{Ba}, \mathrm{Ca}$ and $\mathrm{Sr}$ doped apatite-type lanthanum silicates. Journal of Materials Chemistry 2007;17:2078. 
[18] Bechade E, Julien I, Iwata T, Masson O, Thomas P, Champion E, Fukuda K. Synthesis of lanthanum silicate oxyapatite materials as a solid oxide fuel cell electrolyte. J. Eur. Ceram. Soc. 2008;28:2717.

[19] Jones A, Slater PR, Islam MS. Local defect structures and ion transport mechanisms in the oxygen-excess apatite La-9.67(SiO4)(6)O-2.5. Chemistry of Materials 2008;20:5055.

[20] Orera A, Kendrick E, Apperley DC, Orera VM, Slater PR. Effect of oxygen content on the Si-29 NMR, Raman spectra and oxide ion conductivity of the apatite series, La8+xSr2-x(SiO4)(6)O2+x/2. Dalton Transactions 2008:5296.

[21] Panteix PJ, Julien I, Abelard P, Bernache-Assollant D. Influence of cationic vacancies on the ionic conductivity of oxyapatites. J. Eur. Ceram. Soc. 2008;28:821.

[22] Boyer L, Piriou B, Carpena J, Lacout JL. Study of sites occupation and chemical environment of Eu3+ in phosphate-silicates oxyapatites by luminescence. Journal of Alloys and Compounds 2000;311:143.

[23] Fahey JA, Weber WJ, Rotella FJ. An X-ray and Neutron Powder Diffraction Study of $\mathrm{Ca}_{2+\mathrm{x}} \mathrm{Nd}_{8-}$ ${ }_{x}\left(\mathrm{SiO}_{4}\right)_{6} \mathrm{O}_{2-0.5 x}$ System. Journal of Solid State Chemistry 1985.

[24] Clark LMI, Taylor RE. Radiation loss in the flash method for thermal diffusivity. Journal of Applied Physics 1975;46:714.

[25] E1269-95 A. Standard Test Method for Determining Specific Heat Capacity by Differential Scanning Calorimetry. ASTM International, West Conshohocken, PA.

[26] Schlichting KW, Padture NP, Klemens PG. Thermal conductivity of dense and porous yttriastabilized zirconia. J Mater Sci 2001;36:3003.

[27] Slater PR, Sansom JEH, Tolchard JR. Development of Apatite-Type of Oxide Ion Conductors. The Chemical Record 2004;4:373.

[28] Barin I. Thermochemical data of pure substances. Weinheim, Federal Republic of Germany; New York: VCH, 1993.

[29] Barin I, Knacke O. Thermochemical Properties of Inorganic Substances. Berlin: Springer-Veriag, 1973.

[30] Clarke DR. Materials selection guidelines for low thermal conductivity thermal barrier coatings. Surface \& Coatings Technology 2003;163:67.

[31] Kittel C. Interpretation of the Thermal Conductivity of Glasses. Physical Review 1949;75:972.

[32] White TJ, Dong Z. Structural Derivation and Crystal Chemistry of Apatites. Acta Crystallographica B. 2003;59:1.

[33] Grimvall G. Thermophysical Properties of Materials. Amsterdam: North Holland, 1986.

[34] Klemens PG. The Scattering of Low-Frequency Lattice Waves by Static Imperfections. Proceedings of the Physical Society of London Section A 1955;68:1113. 
[35] Callaway J, von Baeyer HC. Effect of Point Imperfections on Lattice Thermal Conductivity. Physical Review 1960;120:1149.

[36] Callaway J. Model for Lattice Thermal Conductivity at Low Temperatures. Physical Review 1959;113:1046.

[37] Slack GA. Thermal Conductivity of $\mathrm{MgO}, \mathrm{Al}_{2} \mathrm{O}_{3}, \mathrm{MgAl}_{2} \mathrm{O}_{4}$, and $\mathrm{Fe}_{3} \mathrm{O}_{4}$ Crystals from 3 Degrees to 300 Degrees K. Physical Review 1962;126:427.

[38] Berman R, Foster EL, Ziman JM. Thermal Conductivity of Dielectric Crystals. Proceedings of the Royal Society of London Series a-Mathematical Physical and Engineering Sciences.

[39] Roufosse MC, Klemens PG. Lattice Thermal Conductivity of Minerals at High Temperatures. Journal of Geophysical Research 1974;79:703.

[40] Mevrel R, Laizet J-C, Azzopardi A, Leclercq B, Poulain M, Lavingne O, Demange D. Thermal Diffusivity and Conductivity of $\mathrm{Zr}_{1-x} \mathrm{Y}_{x} \mathrm{O}_{2-x / 2}$ Single Crystals. J. Eur. Ceram. Soc. 2004;24:3081.

[41] Cahill DG, Pohl RO. Lattice Vibrations and Heat Transport in Crystals and Glasses. Annual Review of Materials Research 1988;39:93. 
Table 1.

Compositions and Defect Species

\begin{tabular}{|c|c|c|c|c|c|c|c|c|}
\hline Composition & $\mathbf{x}$ & $\mathbf{y}$ & $\begin{array}{l}\text { Atomic } \\
\text { Mass } \\
\text { (amu) }\end{array}$ & $\begin{array}{l}\text { Defect } \\
\text { Type }\end{array}$ & $\begin{array}{c}\text { Defects } \\
\text { (per unit cell) }\end{array}$ & $\begin{array}{c}\text { Density } \\
\text { (g/cc) }\end{array}$ & $\begin{array}{c}\text { Density } \\
(\%)\end{array}$ & Identifier \\
\hline $\mathrm{Gd}_{6} \mathrm{Ca}_{4}\left(\mathrm{SiO}_{4}\right)_{6} \mathrm{O}$ & -2 & 2 & 1670 & $\begin{array}{c}\text { Oxygen } \\
\text { Vacancies }\end{array}$ & 1 & 4.808 & 92 & 1 \\
\hline $\mathrm{Gd}_{7} \mathrm{Ca}_{3}\left(\mathrm{SiO}_{4}\right)_{6} \mathrm{O}_{1.5}$ & -1 & 1 & 1795 & $\begin{array}{c}\text { Oxygen } \\
\text { Vacancies }\end{array}$ & $1 / 2$ & 5.053 & 90 & 2 \\
\hline $\mathrm{Gd}_{8} \mathrm{Ca}_{2}\left(\mathrm{SiO}_{4}\right)_{6} \mathrm{O}_{2}$ & 0 & 0 & 1920 & None & 0 & 6.007 & $>99$ & 3 \\
\hline $\mathrm{Gd}_{8.333} \mathrm{Ca}_{1.5}\left(\mathrm{SiO}_{4}\right)_{6} \mathrm{O}_{2}$ & $1 / 3$ & $-1 / 2$ & 1952 & $\begin{array}{c}\text { Cation } \\
\text { Vacancies }\end{array}$ & $1 / 6$ & 6.261 & $>98$ & 4 \\
\hline $\mathrm{Gd}_{8.666} \mathrm{Ca}\left(\mathrm{SiO}_{4}\right)_{6} \mathrm{O}_{2}$ & $2 / 3$ & -1 & 1984 & $\begin{array}{c}\text { Cation } \\
\text { Vacancies }\end{array}$ & $1 / 3$ & 6.301 & $>99$ & 5 \\
\hline $\mathrm{Gd}_{9.333}\left(\mathrm{SiO}_{4}\right)_{6} \mathrm{O}_{2}$ & $4 / 3$ & -2 & 2049 & $\begin{array}{c}\text { Cation } \\
\text { Vacancies }\end{array}$ & $2 / 3$ & 6.426 & $>99$ & 6 \\
\hline $\mathrm{Gd}_{10}\left(\mathrm{SiO}_{4}\right)_{6} \mathrm{O}_{3}$ & 2 & -2 & 2170 & $\begin{array}{c}\text { Oxygen } \\
\text { Interstitials }\end{array}$ & 1 & 6.561 & $>96$ & 7 \\
\hline
\end{tabular}


Table 1.

\section{Compositions and Defect Species}

\begin{tabular}{|c|c|c|c|c|c|c|c|c|}
\hline Composition & $\mathbf{x}$ & $\mathbf{y}$ & $\begin{array}{c}\text { Atomic } \\
\text { Mass } \\
\text { (amu) }\end{array}$ & $\begin{array}{c}\text { Defect } \\
\text { Type }\end{array}$ & $\begin{array}{c}\text { Defects } \\
\text { (per unit cell) }\end{array}$ & $\begin{array}{c}\text { Density } \\
\text { (g/cc) }\end{array}$ & $\begin{array}{c}\text { Density } \\
(\%)\end{array}$ & Identifier \\
\hline $\mathrm{Gd}_{6} \mathrm{Ca}_{4}\left(\mathrm{SiO}_{4}\right)_{6} \mathrm{O}$ & -2 & 2 & 1670 & $\begin{array}{c}\text { Oxygen } \\
\text { Vacancies }\end{array}$ & 1 & 4.808 & 92 & 1 \\
\hline $\mathrm{Gd}_{7} \mathrm{Ca}_{3}\left(\mathrm{SiO}_{4}\right)_{6} \mathrm{O}_{1.5}$ & -1 & 1 & 1795 & $\begin{array}{c}\text { Oxygen } \\
\text { Vacancies }\end{array}$ & $1 / 2$ & 5.053 & 90 & 2 \\
\hline $\mathrm{Gd}_{8} \mathrm{Ca}_{2}\left(\mathrm{SiO}_{4}\right)_{6} \mathrm{O}_{2}$ & 0 & 0 & 1920 & None & 0 & 6.007 & $>99$ & 3 \\
\hline $\mathrm{Gd}_{8.333} \mathrm{Ca}_{1.5}\left(\mathrm{SiO}_{4}\right)_{6} \mathrm{O}_{2}$ & $1 / 3$ & $-1 / 2$ & 1952 & $\begin{array}{c}\text { Cation } \\
\text { Vacancies }\end{array}$ & $1 / 6$ & 6.261 & $>98$ & 4 \\
\hline $\mathrm{Gd}_{8.666} \mathrm{Ca}\left(\mathrm{SiO}_{4}\right)_{6} \mathrm{O}_{2}$ & $2 / 3$ & -1 & 1984 & $\begin{array}{c}\text { Cation } \\
\text { Vacancies }\end{array}$ & $1 / 3$ & 6.301 & $>99$ & 5 \\
\hline $\mathrm{Gd}_{9.333}\left(\mathrm{SiO}_{4}\right)_{6} \mathrm{O}_{2}$ & $4 / 3$ & -2 & 2049 & $\begin{array}{c}\text { Cation } \\
\text { Vacancies }\end{array}$ & $2 / 3$ & 6.426 & $>99$ & 6 \\
\hline $\mathrm{Gd}_{10}\left(\mathrm{SiO}_{4}\right)_{6} \mathrm{O}_{3}$ & 2 & -2 & 2170 & $\begin{array}{c}\text { Oxygen } \\
\text { Interstitials }\end{array}$ & 1 & 6.561 & $>96$ & 7 \\
\hline
\end{tabular}


(a)

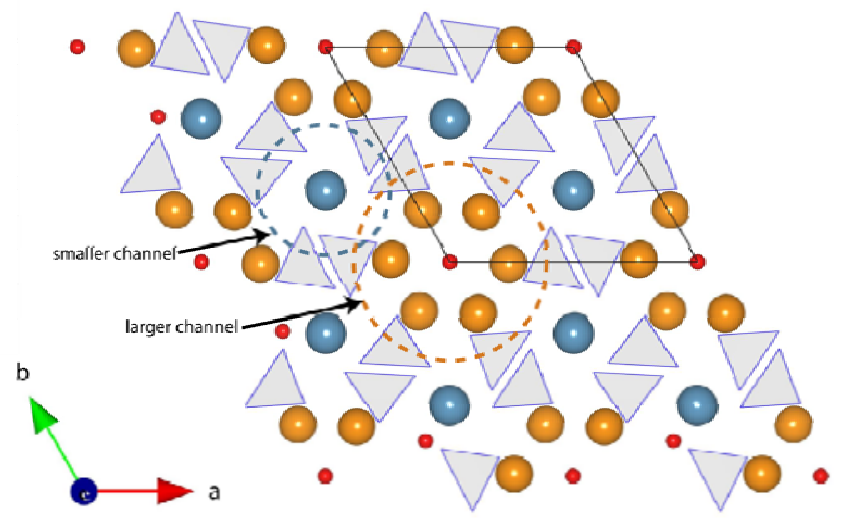

(b)

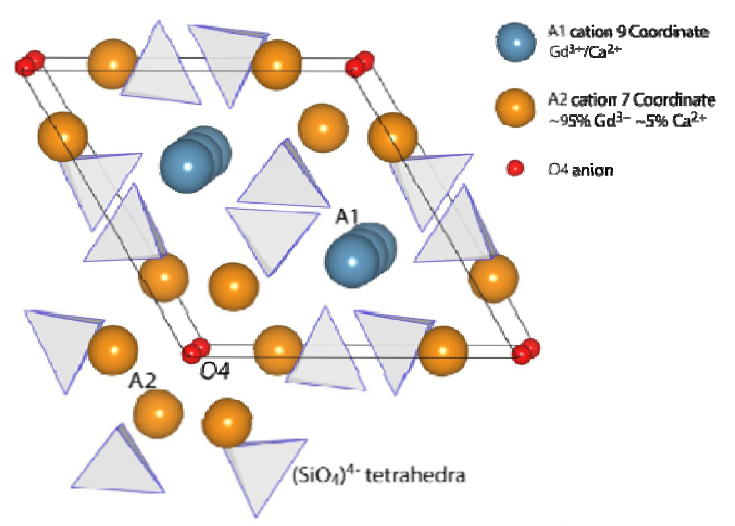




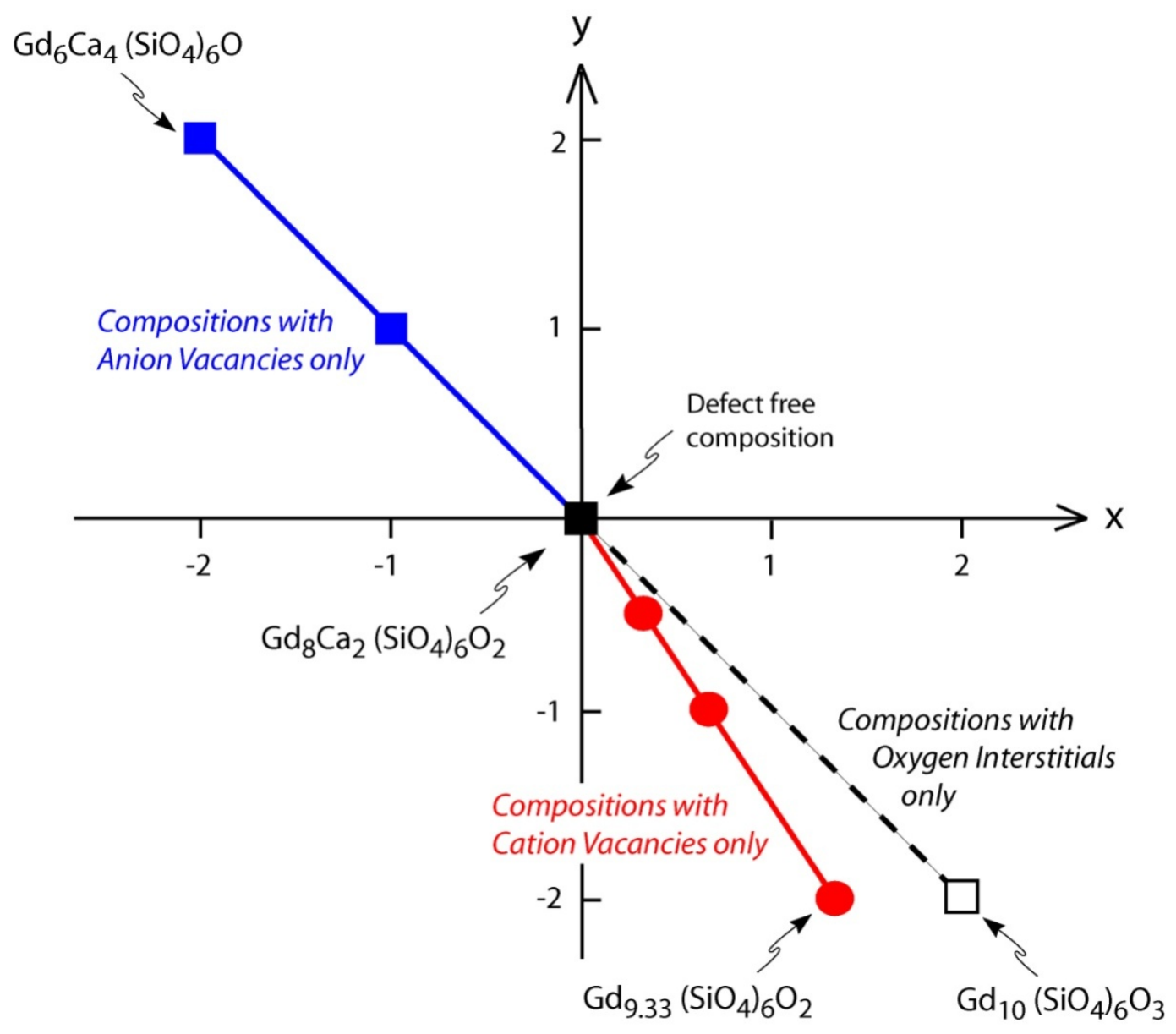




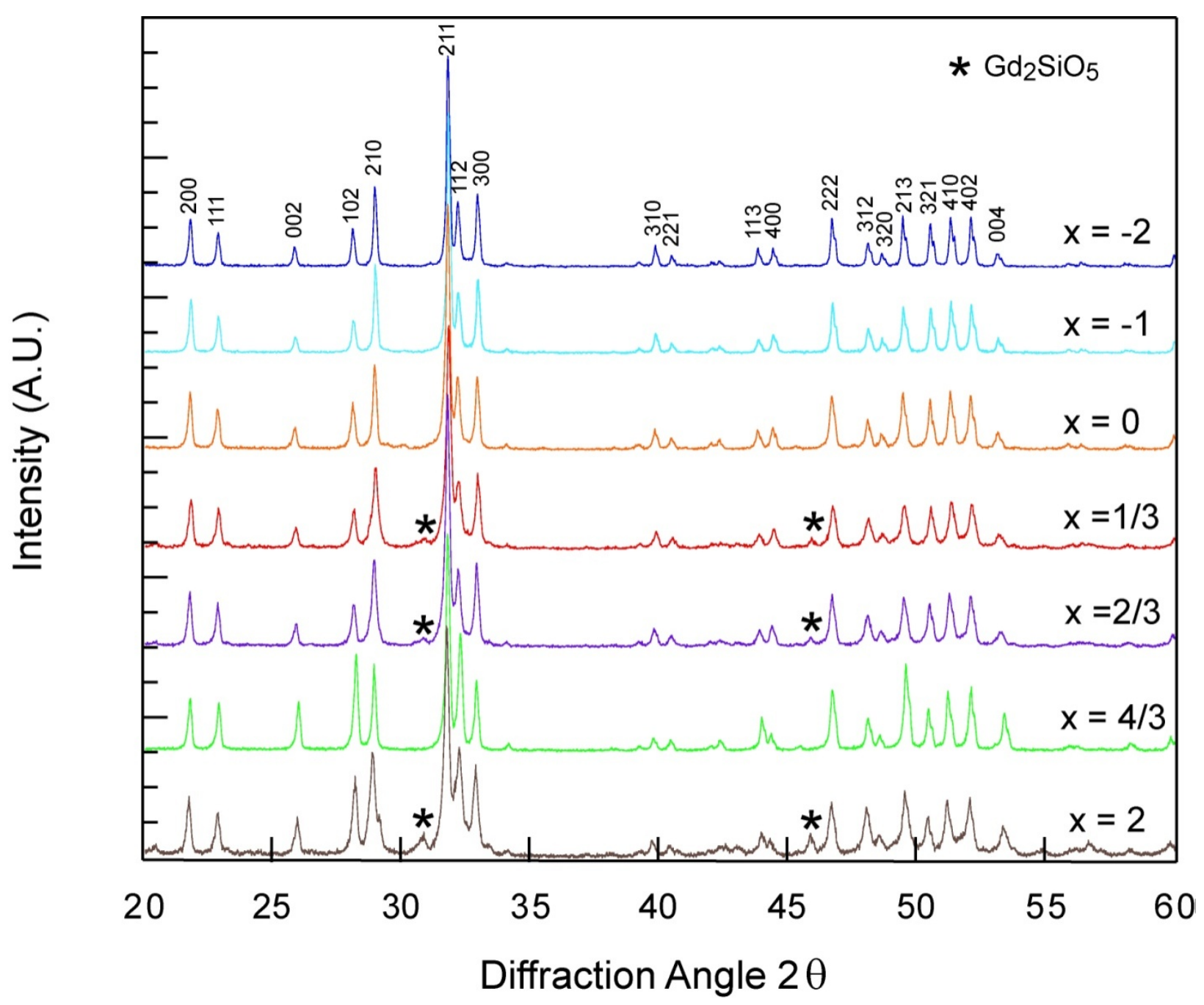

Figure 3. Xray diffraction 


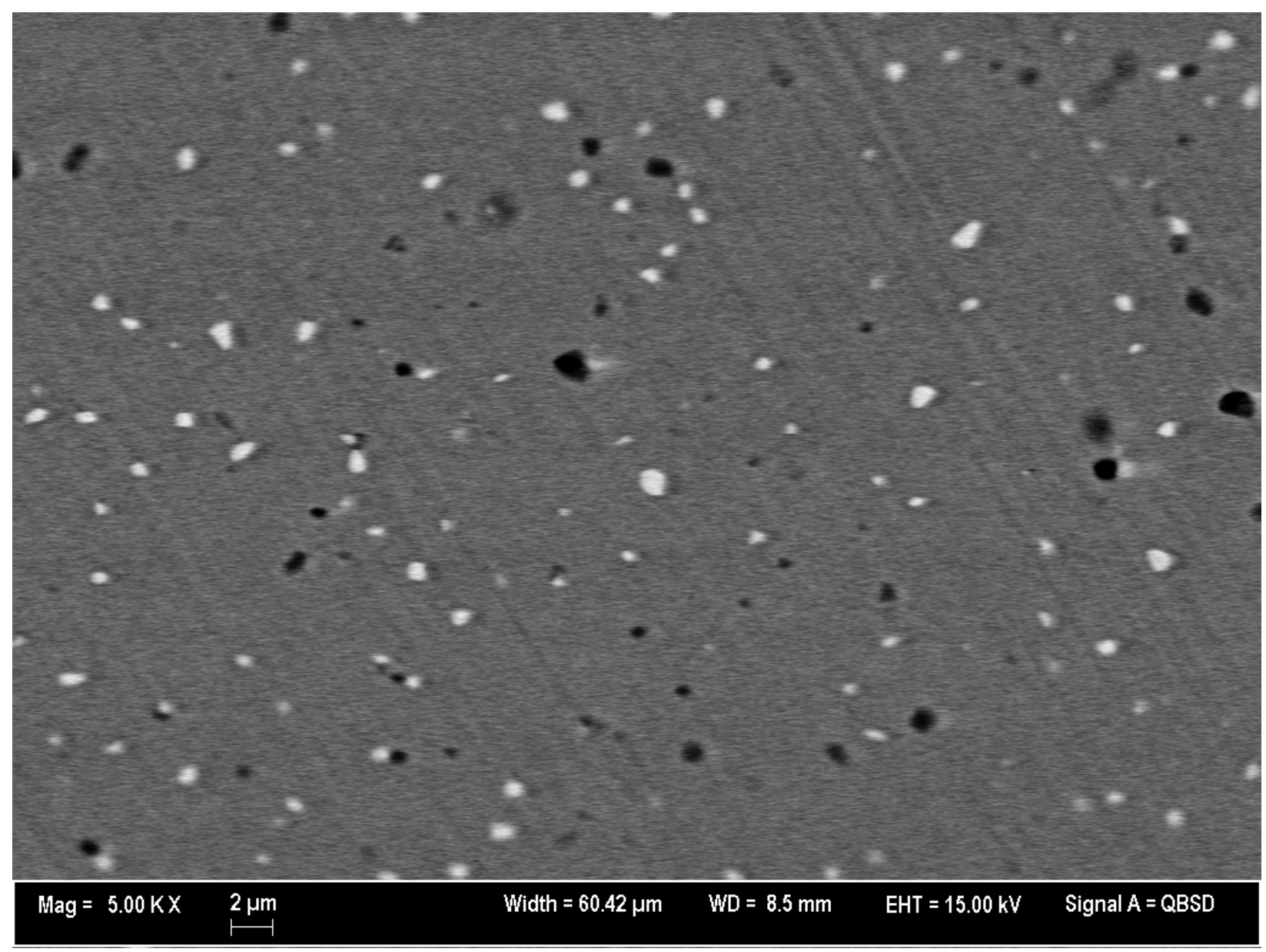

Figure 4. Qu et al. 


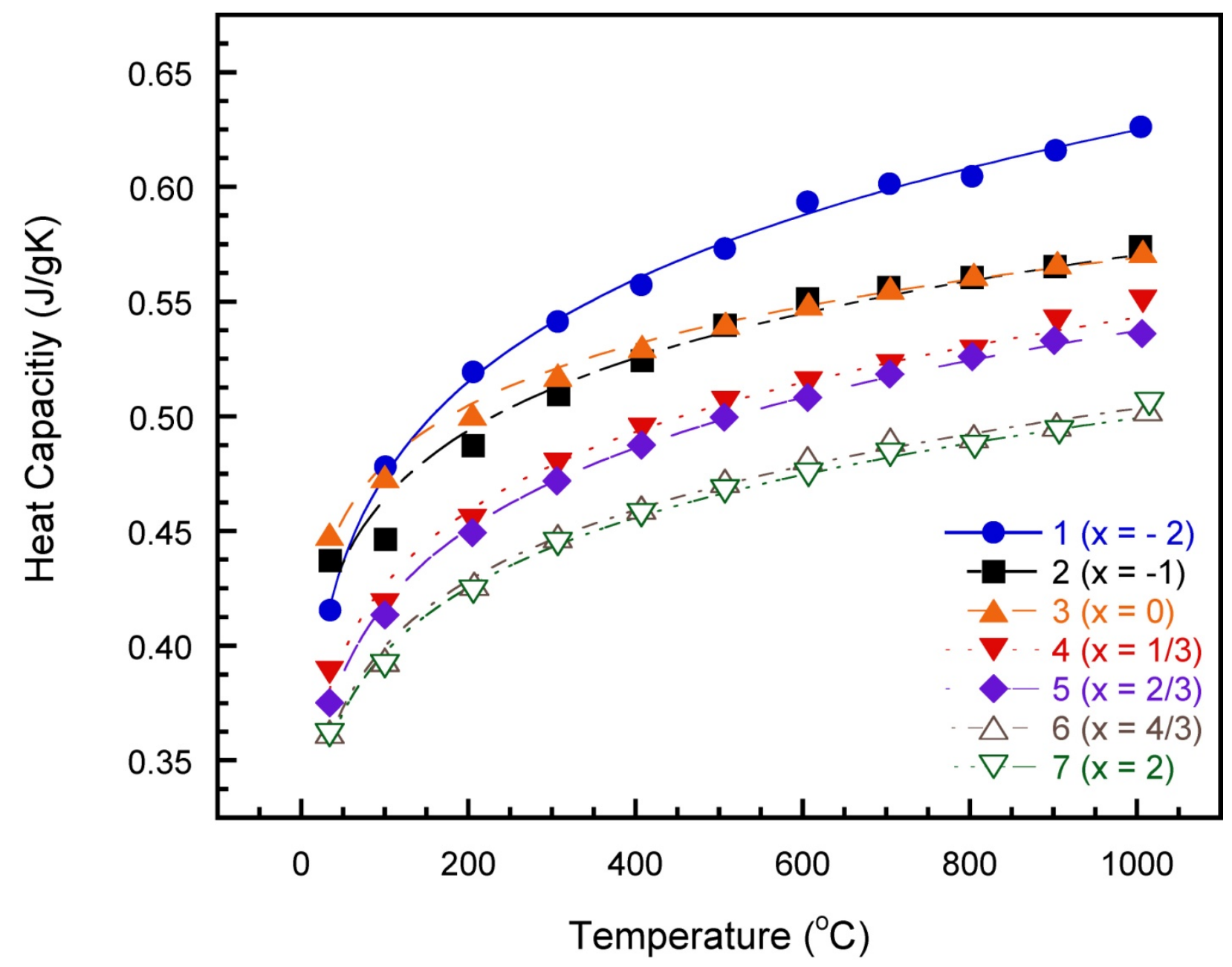

Figure 5. Qu et al. 


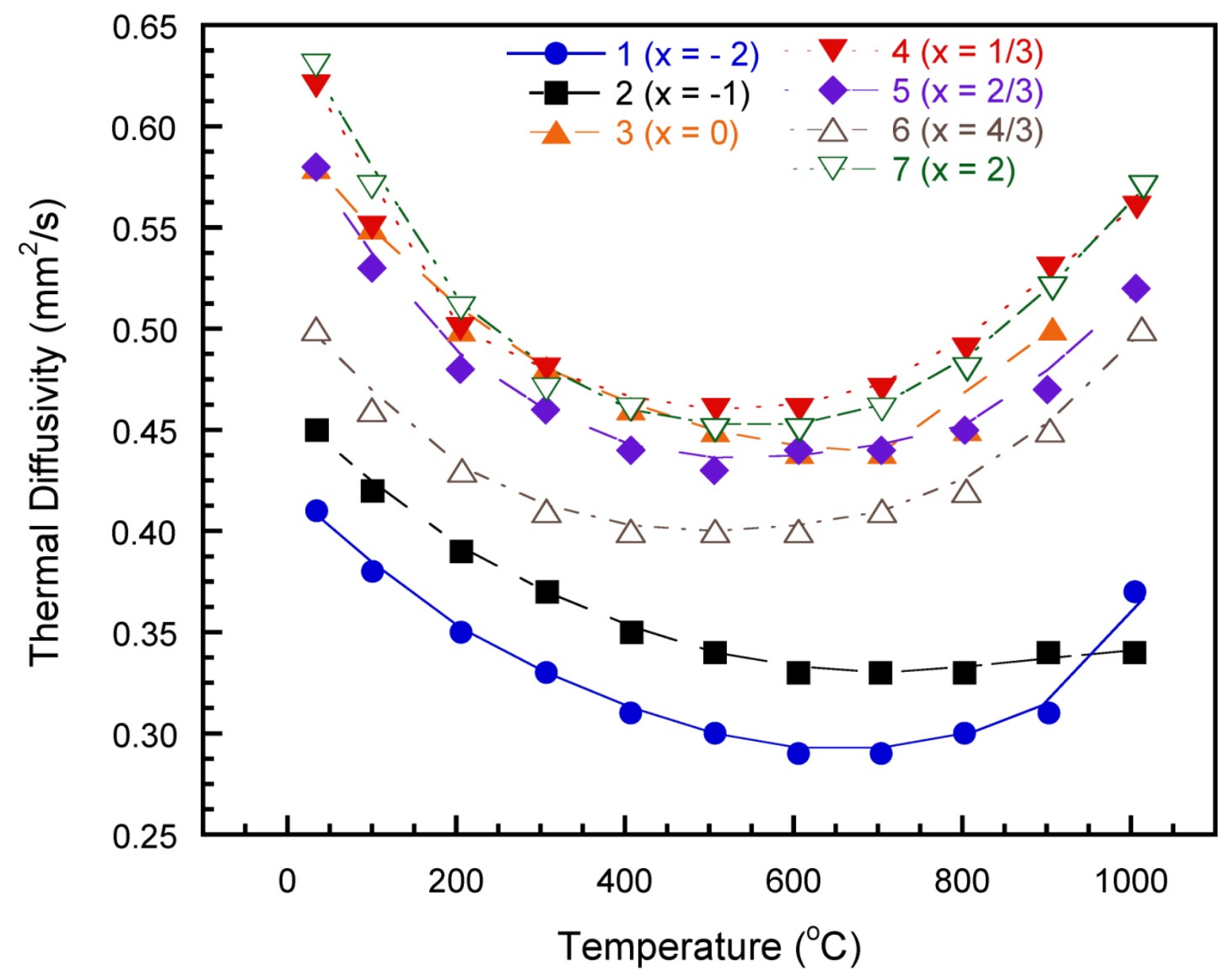

Figure 6. Qu et al. 


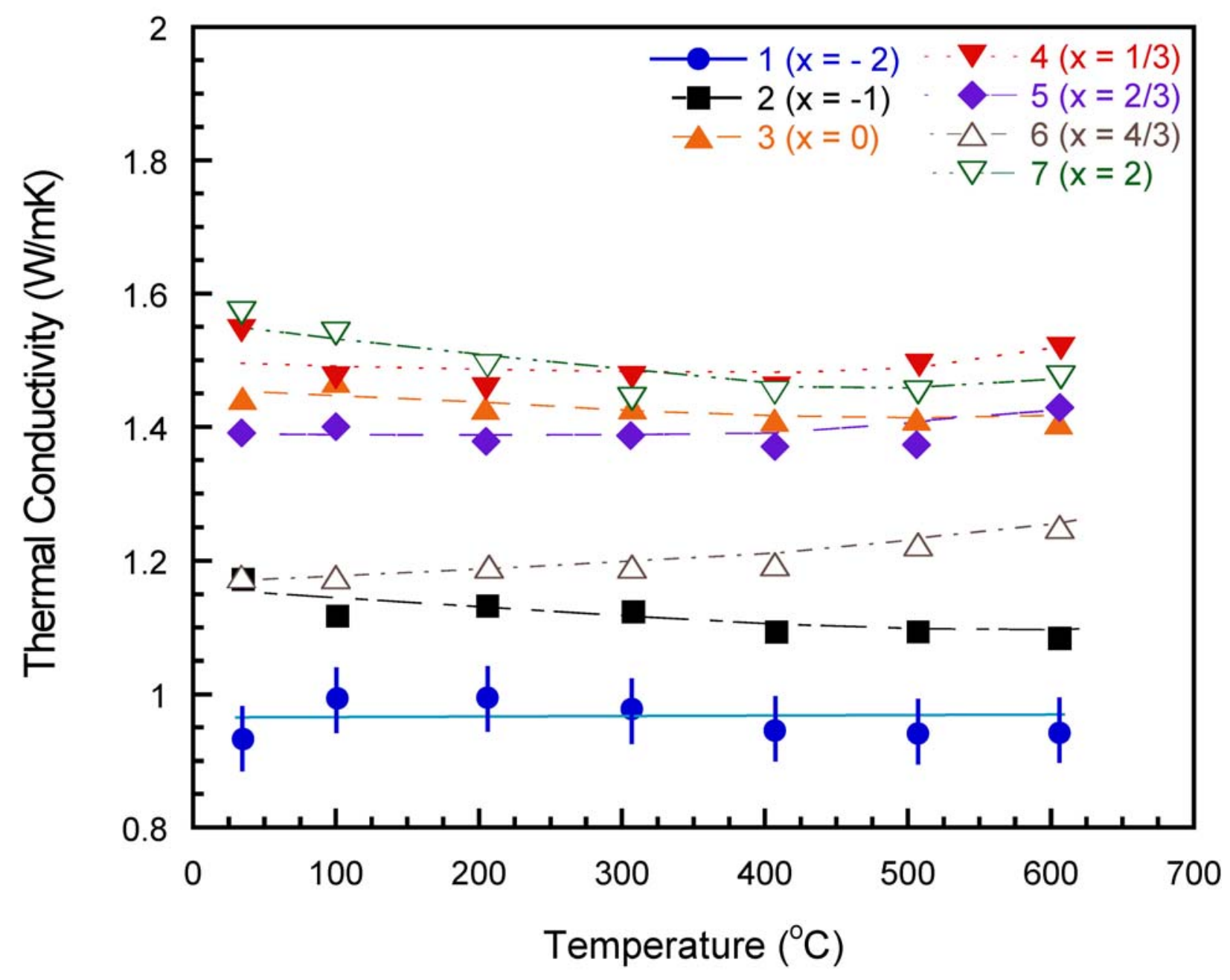

Figure 7. Qu et al. 


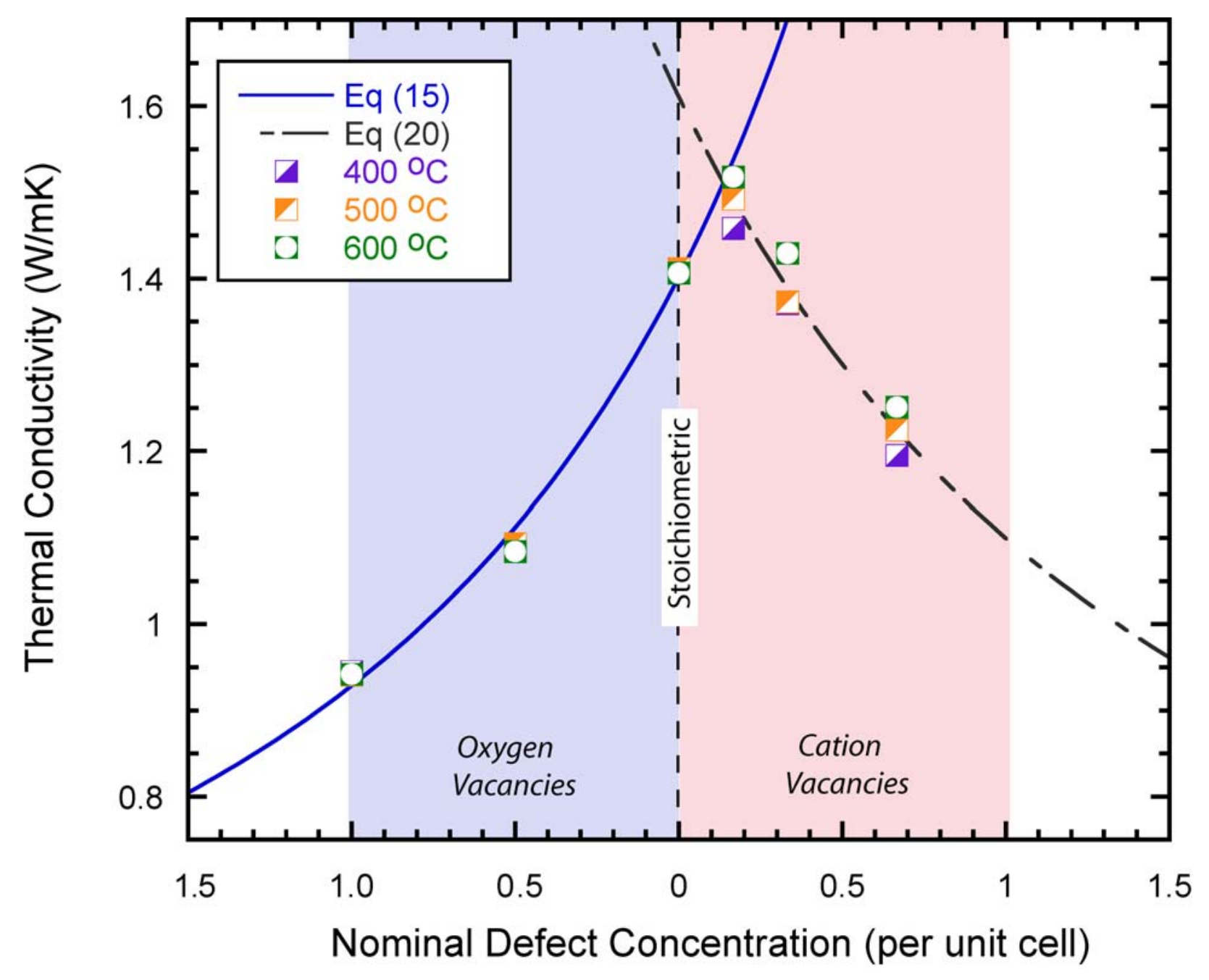

Figure 8. Qu et al. 